\title{
O ENSINO DO KARATÊ NAS AULAS DE EDUCAÇÃO FÍSICA: POSSIBILIDADE DE DESENVOLVIMENTO PSÍQUICO DE CRIANÇAS SÍNDROME DE DOWN
}

\author{
Rodrigo Pereira de Carvalho, Janaína Pereira Duarte Bezerra, Rafael César Ferrari dos Santos \\ Universidade do Oeste Paulista - UNOESTE, Graduação em Educação Física Bacharelado, Presidente Prudente, SP. E- \\ mail:rodrigordgcarvalho@gmail.com
}

\begin{abstract}
RESUMO
A Teoria Histórico-Cultural defende que a formação do psiquismo se delineia a partir das condições presentes na realidade desenvolvendo funções psicológicas superiores. O objetivo deste estudo foi investigar condições teórico-metodológicas para que a Educação Física seja promotora de desenvolvimento psíquico em estudantes Síndrome de Down (SD). A metodologia constou de um experimento didático com o esporte Karatê, onde participaram alunos com SD de 12 a 16 anos, matriculados na Associação de Pais e Amigos dos Excepcionais de Presidente Prudente/SP. As intervenções ocorreram na própria instituição e cada uma durou 60 minutos totalizando 20 horas/aula. Os resultados foram o avanço no desenvolvimento da memória e atenção dos alunos com SD, pois a cada intervenção se lembravam de golpes do karatê e ações realizadas, e respondiam as perguntas prontamente. Concluímos que uma sequência didática a partir do karatê contribui para o desenvolvimento da memória e atenção de alunos com Síndrome de Down.

Palavras-chave: Ensino de lutas, Organização didática, Síndrome de Down, Desenvolvimento do Psiquismo, Função psicológica superior.
\end{abstract}

\section{THE KARATE TEACHING IN THE CLASSES OF PHYSICAL EDUCATION: POSSIBILITY OF PSYCHIC DEVELOPMENT OF CHILDREN DOWN SYNDROME}

\begin{abstract}
The Historical-Cultural Theory defends that the formation of the psychism delineates from the present conditions in the reality developing superior psychological functions. The objective of this study was to investigate theoretical-methodological conditions for Physical Education to be a promoter of psychic development in Down Syndrome students (SD). The methodology consisted of a didactic experiment with the sport Karate, where students with SD of 12 to 16 years, enrolled in the Association of Parents and Friends of the Exceptional of Presidente Prudente / SP participated. The interventions took place in the institution itself and each lasted 60 minutes totaling 20 hours / class. The results were the advance in the development of the memory and attention of the students with SD, because each intervention remembered karate blows and performed actions, and answered the questions promptly. We conclude that a didactic sequence from karate contributes to the development of the memory and attention of students with Down Syndrome.
\end{abstract}

Keywords: Teaching of struggles, Teaching organization, Down Syndrome, Development of Psychism, Superior psychological function. 


\section{INTRODUÇÃO}

A Educação Física tem diferentes possibilidades para promover a aprendizagem e desenvolvimento de Estudantes Público Alvo da Educação Especial. Este trabalho centra-se em discussões acerca de práticas educativas vinculadas à prática do Karatê com crianças e adolescentes. Nesse sentido, compreendem-se os sujeitos de forma totalizada, superando assim, as dicotomias entre corpo e mente tão presente nesta área de conhecimento.

Considerando que a apropriação do conhecimento por meio de sequências didáticas é o que promove o desenvolvimento psíquico segundo a Teoria Histórico - Cultural, os EPAEEs, no nosso caso, os com Síndrome de Down, também são sujeitos de aprendizagem e necessitam que as atividades organizadas favoreçam o desenvolvimento das formas complexas do pensamento mediante a mobilização das Funções Psicológicas Superiores (FPS), que não se formam de maneira espontânea, mas com um ensino dirigido e planejado para este fim.

As complexas funções superiores, segundo Vigotski (1991), referem-se a mecanismos intencionais, ações conscientemente controladas, que nos dão a possibilidade de independência em relação a circunstâncias do momento e espaço presente e originam-se nas relações sociais que o indivíduo estabelece com o mundo. Portanto, a imaginação, a memória, a atenção, dentre outras funções passam a ser intencionalmente controladas.

Nesse contexto, e entendendo que o Karatê é uma produção humana e que na estrutura dessa atividade estão incorporados conceitos que favorecem o desenvolvimento dos sujeitos surge a seguinte pergunta de pesquisa: Como organizar o ensino do Karatê para favorecer o desenvolvimento do psiquismo de crianças com Síndrome de Down?

Consideramos que a tomada de consciência dos conceitos envolvidos nas atividades corporais possibilita o desenvolvimento das Funções Psicológicas Superiores (FPS) que permitem o domínio das ações corporais presentes nas atividades da cultura corporal, seja a ação própria, como a ação dos demais sujeitos envolvidos na atividade.

A partir de todo o exposto, esta pesquisa justificou-se pela necessidade de refletir sobre e as relações existentes entre os conteúdos presentes nas atividades corporais, especificamente da modalidade Karatê na atividade de lutas e as funções complexas do pensamento (imaginação, atenção, percepção, memória, raciocínio), de modo especial, o pensamento teórico, com o intuito de buscar condições teórico-metodológicas para que a Educação Física gere aprendizagens promotoras do desenvolvimento dos estudantes Síndrome de Down.

Nessa direção, o objetivo do presente estudo foi investigar condições teóricometodológicas para que o ensino de Educação Física gere aprendizagens promotoras do desenvolvimento do psiquismo dos estudantes com Síndrome de Down.

\section{METODOLOGIA}

O presente estudo foi aprovado pelo comitê de ética e pesquisa sob número do CAAE: 80534017.3.0000.5515 na plataforma Brasil. Inicialmente realizamos um estudo bibliográfico com a intenção de apreender o processo do ensino de lutas nas aulas de Educação Física, "[...] localizar o que já se sabe, quais a principais lacunas onde se encontram os principais entraves teóricos [...]" (LUNA, 1999, p. 82), divergências, tensão e unidade entre as concepções teóricas acerca do ensino de Educação Física em contexto escolar. Espera-se que essa análise revele pressupostos teóricos que subsidiarão a elaboração do segundo momento dessa pesquisa.

No segundo momento, ainda de caráter bibliográfico, recorrer aos pressupostos da Teoria Histórico-Cultural, como instrumento de leitura para a panorâmica encontrada sobre o ensino de lutas na escola.

No terceiro momento foi organizado um experimento didático com base nos pressupostos didáticos levantados, tendo como objetivo a aprendizagem de conceitos do movimento corporal pelo conteúdo concernente a atividade de lutas alunos Síndrome de Down matriculados na APAE 
Associação de Pais e Amigos dos Excepcionais do Município de Presidente Prudente/SP, contando inicialmente com 20 horas/aula para o seu desenvolvimento.

O experimento didático é embasado nos princípios do método genético experimental utilizado por Vigotski (2003) para o estudo da elaboração de conceitos e na metodologia do experimento formativo apresentada por Davidov (1988).

Segundo Davidov, o experimento didático:

[...] caracteriza-se pela intervenção ativa do pesquisador nos processos mentais que ele estuda. Neste sentido, ele difere essencialmente do experimento de constatação, que somente enfoca o estado já formado e presente de uma formação mental. A realização do experimento formativo pressupõe a projeção e modelação do conteúdo das formações mentais novas a serem formadas, dos meios psicológicos e pedagógicos e das vias de sua formação [...] plasma uma combinação (unidade) entre a investigação do desenvolvimento mental das crianças e a educação e ensino destas mesmas crianças (DAVIDOV, 1988, p. 196, tradução nossa).

O experimento foi elaborado e aplicado pelo pesquisador e teve como fontes de análise as atividades dos estudantes, os relatos verbais diretos fornecidos pelas gravações em vídeo que foram feitas durante a realização das atividades. Os dados foram coletados no mesmo tempo em que utilizaremos os princípios didáticos, levantados no segundo momento da pesquisa, com objetivo de investigar o impacto desse tipo de ensino na aprendizagem dos sujeitos envolvidos na pesquisa.

Os procedimentos foram organizados tanto em situações compartilhadas como em situações individuais, a fim de que haja uma maior explicitação do pensamento dos alunos. Os relatos verbais e comportamentais oferecerão dados para a análise. Em nosso experimento didático, a atenção foi voltada para o ensino e para a aprendizagem, pois temos a intenção de reconhecer se o ensino organizado com base nos princípios didáticos levantados favorecerá a aprendizagem dos estudantes Síndrome de Down, em outras palavras, se eles passam a ter maior domínio da própria ação, bem como das ações dos demais colegas envolvidos na atividade.

\section{RESULTADOS}

Foi realizada 20 intervenções, sendo 1 hora cada intervenção totalizando 20 horas de intervenções junto aos alunos da APAE do Presidente Prudente.

Inicialmente as crianças não lembravam dos golpes, ações corporais presentes no karate, a execução era apenas mecânica, realizadas apenas após o pesquisador demonstrar o movimento. Após a organização planejada do ensino, os alunos passaram a executar os mesmos golpes, mas dentro de ações dentro da atividade proposta, onde exigia dos alunos a solução de uma problemática, elaborada pelo pesquisador, os alunos começaram a assimilar os conceitos presentes nas ações corporais e passaram a agir com essas ações livremente dentro das atividades desenvolvidas, essa observação foi realizada junto aos alunos na decima sétima intervenção.

\section{DISCUSSÃO}

De acordo com Vigotski (2007) e seus colaboradores sobre os processos de desenvolvimento e aprendizagem trazem elementos que possibilitam pensar que os conhecimentos artísticos e científicos quando apropriados pelos alunos, transformam-se, em elementos mediadores que permitem o desenvolvimento de funções psicológicas superiores.

As complexas funções superiores, segundo Vigotski (1991), referem-se a mecanismos intencionais, ações conscientemente controladas, que nos dão a possibilidade de independência em relação a circunstâncias do momento e espaço presente e originam-se nas relações sociais que o indivíduo estabelece com o mundo. Portanto, a imaginação, a memória, a atenção, dentre outras funções passam a ser intencionalmente controladas. 
No entanto, a relação entre a aprendizagem dos conceitos científicos e o desenvolvimento não é algo imediato, mas mediado pelo ensino, e, a depender dessa mediação, pode ou não promover o desenvolvimento dos estudantes. Para Vigotski (2007), somente uma adequada organização do aprendizado resulta em desenvolvimento mental e põe em movimento vários processos de desenvolvimento. O desenvolvimento mental que resulta da aprendizagem de pensamento teórico.

Essa compreensão sobre o papel da escolarização no desenvolvimento humano, não se refere a uma área de conhecimento específica, mas à apropriação de todos os conhecimentos já produzidos pela humanidade, o que inclui, portanto, os conhecimentos que são objetos de ensino na disciplina de Educação Física.

De acordo com Leontiev:

A primeira condição de toda a atividade é uma necessidade. Todavia, em si, a necessidade não pode determinar a orientação concreta de uma atividade, pois é apenas no objeto da atividade que ela encontra sua determinação: deve, por assim dizer, encontrar-se nele. Uma vez que a necessidade encontra a sua determinação no objeto (se "objetiva" nele), o dito objeto torna-se motivo da atividade, aquilo que o estimula. (Leontiev, 1978, p. 107108)

\section{CONCLUSÃO}

Concluímos que uma sequência didática a partir do karatê contribui para o desenvolvimento da memória e atenção de alunos com Síndrome de Down.

\section{REFERÊNCIAS}

DAVIDOV, V. V. La enseñanza escolar y El desarrollo psíquico. Editorial Progresso, 1988.

GALUCH, Maria Terezinha B.; SFORNI, Marta Sueli de Faria. Interfaces entre políticas educacionais, prática pedagógica e formação humana. Práxis Educativa, Ponta Grossa, v.6, n1, p.55-66, jan.-jun. 2011.

LUNA, S. V. Planejamento de Pesquisa: Uma introdução. São Paulo: EDUC, 2009.

VIGOTSKII, L.S. Aprendizagem e desenvolvimento intelectual na idade pré-escolar. In: Vigotskii, L.S; Luria, A.R; Leontiev, A.N. Linguagem, desenvolvimento e aprendizagem. São Paulo: ICONE, 1991

VIGOTSKI, L. S. A Formação Social da mente. 7. ed. São Paulo: Martins Fontes, 2007.

VIGOTSKI, L. S. A construção do pensamento e da linguagem. São Paulo: Martins Fontes, 2009.

VIGOTSKII, L.S. Aprendizagem e desenvolvimento intelectual na idade pré-escolar. In: Vigotskii, L.S; Luria, A.R; Leontiev, A.N. Linguagem, desenvolvimento e aprendizagem. São Paulo: ICONE, 1991

LEONTIEV, A., (1978). Sobre o desenvolvimento histórico da consciência. In: LEONTIEV, A. $O$ desenvolvimento do psiquismo. Lisboa: Horizonte Universitário, p. 89-142. 